\title{
Stable isotopes provide revised global limits of aerobic methane emissions from plants
}

\author{
D. F. Ferretti ${ }^{1,2}$, J. B. Miller ${ }^{3}$, J. W. C. White ${ }^{1}$, K. R. Lassey ${ }^{2}$, D. C. Lowe ${ }^{2}$, and D. M. Etheridge ${ }^{4}$ \\ ${ }^{1}$ University of Colorado, Boulder, CO, USA \\ ${ }^{2}$ National Institute of Water and Atmospheric Research Ltd, Wellington, New Zealand \\ ${ }^{3}$ National Oceanographic and Atmospheric Administration, Boulder, CO, USA \\ ${ }^{4}$ Marine and Atmospheric Research, Commonwealth Scientific and Industrial Research Organisation, Aspendale, Victoria, \\ Australia
}

Received: 3 May 2006 - Published in Atmos. Chem. Phys. Discuss.: 7 July 2006

Revised: 30 October 2006 - Accepted: 2 January 2007 - Published: 17 January 2007

\begin{abstract}
Recently Keppler et al. (2006) discovered a surprising new source of methane - terrestrial plants under aerobic conditions, with an estimated global production of 62 $236 \mathrm{Tg} \mathrm{yr}^{-1}$ by an unknown mechanism. This is $\sim 10-40 \%$ of the annual total of methane entering the modern atmosphere and $\sim 30-100 \%$ of annual methane entering the preindustrial ( 0 to $1700 \mathrm{AD}$ ) atmosphere. Here we test this reported global production of methane from plants against ice core records of atmospheric methane concentration $\left(\mathrm{CH}_{4}\right)$ and stable carbon isotope ratios $\left(\delta^{13} \mathrm{CH}_{4}\right)$ over the last 2000 years. Our top-down approach determines that global plant emissions must be much lower than proposed by Keppler et al. (2006) during the last 2000 years and are likely to lie in the range $0-46 \mathrm{Tg} \mathrm{yr}^{-1}$ and $0-176 \mathrm{Tg} \mathrm{yr}^{-1}$ during the preindustrial and modern eras, respectively.
\end{abstract}

\section{Introduction}

Atmospheric methane $\left(\mathrm{CH}_{4}\right)$ is an important greenhouse gas that impacts atmospheric chemistry and has almost tripled in abundance since pre-industrial times. The inclusion of large methane emissions from plants via an unknown biological production mechanism as proposed by Keppler et al. (2006) has important multidisciplinary scientific implications. Consequently the discovery is currently subject to methodological scrutiny and requires substantial experimental validation under realistic field conditions. The Keppler et al. (2006) methodology assumed that measured emissions from chambered plants were globally representative and scaleable to annual net primary production (adjusted for seasonal and daylight lengths for different plant types). Extrapolation of their

Correspondence to: D. F. Ferretti

(d.ferretti@niwa.co.nz) bottom-up measurements resulted in large uncertainties and could overestimate global plant emissions.

Emitted methane from tropical plants has been suggested (Keppler et al., 2006) to help explain the surprisingly high methane concentrations observed by satellite over tropical forests (Frankenberg et al., 2005, 2006). Recently reported methane emissions from Brazilian forests $\left(4-38 \mathrm{Tg} \mathrm{yr}^{-1}\right.$ Carmo et al., 2006) and from Venezuelan savannah and forests ( $\sim 30-60 \mathrm{Tg} \mathrm{yr}^{-1}$ Crutzen et al., 2006) may be produced by plants but could also include some contribution from anaerobic methane sources. Alternative calculations to extrapolate the Keppler et al. (2006) results to the global scale, however, estimate that global plant emissions are only $\sim 10-60 \mathrm{Tg} \mathrm{yr}^{-1}$ based on foliage biomass and photosynthetic rates (Kirschbaum et al., 2006) or $\sim 53 \mathrm{Tg} \mathrm{yr}^{-1}$ based on leafy and non-leafy biomass (Parsons et al., 2006), and are much lower than the $62-236 \mathrm{Tg} \mathrm{yr}^{-1}$ deduced by Keppler et al. (2006), while other model simulations suggest that modern and pre-industrial global plant emissions are as large as $\sim 125 \mathrm{Tg} \mathrm{yr}^{-1}$ and $\sim 85 \mathrm{Tg} \mathrm{yr}^{-1}$, respectively (Houweling et al., 2006) - see Schiermeier (2006) for summary of recent estimates.

Although a prominent role of plant emissions in the preindustrial atmosphere was proposed by Keppler et al. (2006), here we show that plant emissions are likely to be much smaller than they initially proposed and are not essential to close the isotopic mass balance of atmospheric methane.

\section{Methods}

To determine tighter limits on global plant emissions we first postulate fossil and biomass burning emissions in the pre industrial and modern eras then calculate anaerobic and aerobic sources to balance observed atmospheric composition. The

Published by Copernicus GmbH on behalf of the European Geosciences Union. 
Table 1. Upper limits of global $\mathrm{CH}_{4}$ emissions from plants.

To calculate the "Maximum Estimate" of the plant source, we use lowest reported values of fossil and biomass burning emissions (see notes a and b). The plant source upper limits decrease further in the "Best Estimate" calculations where more likely values are used for fossil and biomass burning emissions (see notes c and d). A $\mathrm{C}_{3}: \mathrm{C}_{4}$ plant type ratio of 60:40 is consistent with previous studies (Ferretti et al., 2005; Keppler et al., 2006) and with global $\delta^{13} \mathrm{CH}_{4}$ source signatures from biomass burning, plants, and anaerobic sources of $-19.8 \%$ o $-49.8 \%$, and $-60 \%$, respectively. Anaerobic and aerobic plant emissions cover a range because we allow for: (i) uncertainties in the weighted-mean value of the $\mathrm{CH}_{4}$ sink fractionation factor between $-7 \%$ and $-5 \%$ (Lassey et al., 2005); and (ii) variations in the $\mathrm{C}_{3}: \mathrm{C}_{4}$ plant type ratio from 40:60 to 60:40. The resulting variation in the weighted-mean $\delta^{13} \mathrm{CH}_{4}$ source signatures are: biomass burning ( -19.8 to $-17.2 \%$ ), plant ( -49.8 to $-48.7 \%$ ), and anaerobic sources ( -60 to $-58 \%$ ) (see Table 2 ). The fossil source signature is held constant at $-40 \%$.

\begin{tabular}{|c|c|c|c|c|c|}
\hline & Source Type & $\begin{array}{l}0 \text { to } 1000 \mathrm{AD} \\
\text { emissions } \\
\left(\mathrm{Tg} \mathrm{yr}^{-1}\right)\end{array}$ & $\begin{array}{l}\text { Changes } \\
1000 \text { to } 1700 \mathrm{AD}^{\mathrm{e}} \\
(\mathrm{Tg})\end{array}$ & $\begin{array}{l}1700 \mathrm{AD} \\
\text { emissions } \\
\left(\mathrm{Tg} \mathrm{yr}^{-1}\right)\end{array}$ & $\begin{array}{l}2000 \mathrm{AD} \\
\text { emissions } \\
\left(\mathrm{Tg} \mathrm{yr}^{-1}\right)\end{array}$ \\
\hline \multirow{4}{*}{ 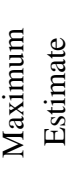 } & Fossil $^{\mathrm{a}}$ & 10 & (0) & 10 & 82 \\
\hline & Biomass burning $^{b}$ & 10 & $(-5)$ & 5 & 21 \\
\hline & Anaerobic & 178-91 & $(+41)$ & $222-128$ & $487-274$ \\
\hline & Aerobic plant & $34-121$ & $(-22)$ & $9-103$ & $0-213$ \\
\hline \multirow{4}{*}{ 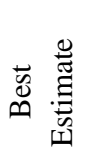 } & Fossil $^{\mathrm{c}}$ & 19 & (0) & 19 & 91 \\
\hline & Biomass burning $^{\mathrm{d}}$ & 25 & $(-10)$ & 15 & 26 \\
\hline & Anaerobic & $188-144$ & $(+22)$ & $212-166$ & $473-297$ \\
\hline & Aerobic plant & $0-44$ & $(+2)$ & $0-46$ & $0-176$ \\
\hline
\end{tabular}

\footnotetext{
${ }^{a}$ The fossil source includes $\mathrm{CH}_{4}$ emissions from natural geologic and ocean sources together with anthropogenic coal mining and energy use with a $\delta^{13} \mathrm{CH}_{4}$ signature of $-40 \%$. We assume no anthropogenic fossil emissions in the interval 0-1700 AD and take the lowest reported estimates of both natural (Judd et al., 1993) and anthropogenic (Scheehle and Kruger, 2006) fossil emissions.

b A lower natural limit of $\sim 1.2 \mathrm{Pg} \mathrm{C} \mathrm{yr}^{-1}$ from lightning induced wildfires (Venevsky, 2006) translates to $\sim 10 \mathrm{Tg} \mathrm{yr}^{-1} \mathrm{of} \mathrm{CH}_{4}$ from biomass burning, using a typical emission factor of $9 \mathrm{mmol} \mathrm{CH} 4 / \mathrm{mol} \mathrm{C}$ derived from Andreae and Merlet (2001). We ignore pre-industrial anthropogenic biomass burning emissions. Our lower limit of modern biomass burning emissions is determined by neglecting natural biomass burning emissions and assuming only anthropogenic emissions (Scheehle and Kruger, 2006).

${ }^{\mathrm{c}}$ Here we use larger and more commonly reported values for natural fossil emissions (Houweling et al., 2000) although it is possible that natural fossil emissions could be much higher (e.g. Etiope, 2004). We use a conservative estimate for modern anthropogenic fossil emissions (Scheehle and Kruger, 2006).

${ }^{\mathrm{d}}$ Here we use larger and more likely pre-industrial biomass burning emissions (Ferretti et al., 2005; Venevsky, 2006; Subak, 1994). We use conservative values for modern biomass burning emissions from natural $\left(5 \mathrm{Tg} \mathrm{yr}^{-1}\right)$ and anthropogenic (Scheehle and Kruger, 2006) sources.

e These source changes are approximate and required to match the $2 \% o \delta^{13} \mathrm{CH}_{4}$ depletion and the $14 \mathrm{Tg}$ total source increase between 1000 to $1700 \mathrm{AD}$ determined from ice core data (Ferretti et al., 2005). Note 0 to $1000 \mathrm{AD}$ has a total source of $232 \mathrm{Tg} \mathrm{yr}^{-1}$ and $\delta^{13} \mathrm{CH}_{4} \approx-47 \%$ o, $2000 \mathrm{AD}$ has a total source of $590 \mathrm{Tg}$ yr ${ }^{-1}$ and $\delta^{13} \mathrm{CH}_{4} \approx-47 \%$.

${ }^{\mathrm{f}}$ We have deduced the individual methane source components so that the overall isotopic signature of the "Maximum Estimate" and "Best Estimate" are identical. However our presented results have been rounded so recalculating the overall isotopic signature of the "Maximum Estimate" and "Best Estimate" should not be expected to give exact results.
}

atmospheric constraint is given by $\mathrm{CH}_{4}$ mass balance and stable carbon-isotope ratios $\left(\delta^{13} \mathrm{CH}_{4}\right)$ over the last 2000 years recovered from ice core air bubbles (Ferretti et al., 2005). From independent assessments of fossil and biomass burning we take the lowest reported emissions to constrain the anaerobic/aerobic mix in our "Maximum Estimate" of the plant source, while higher and more probable fossil and biomass burning emissions constrain our "Best Estimate" of the plant source (see Table 1). We allow for $\delta^{13} \mathrm{CH}_{4}$ source signature variations and $\mathrm{CH}_{4}$ sink fractionation uncertainties (see Tables 1 and 2).

\section{Results and discussion}

Our results (Table 1) show that the "Maximum Estimate" of pre-industrial and modern global plant emissions are in the ranges $34-121 \mathrm{Tg} \mathrm{yr}^{-1}$ and $0-213 \mathrm{Tg} \mathrm{yr}^{-1}$, respectively, lower than reported by Keppler et al. (2006). However, global biomass burning emissions at $1700 \mathrm{AD}$ are very unlikely to be as low as $5 \mathrm{Tg} \mathrm{yr}^{-1}$ because even lightninginduced wildfires alone (i.e. zero anthropogenic contribution) are likely to be more than $5 \mathrm{Tg} \mathrm{yr}^{-1}$ (see Table 1 , note b) and higher pre-industrial biomass burning and fossil emissions in our "Best Estimate" compare well with other studies (Ferretti et al., 2005; Subak, 1994; Scheehle and Kruger, 2006; Houweling et al., 2000). Thus our "Best Estimate" is a more reasonable methane budget reconstruction, suggesting that pre-industrial and modern plant emissions are most likely to be in the ranges $0-46 \mathrm{Tg} \mathrm{yr}^{-1}$ and $0-176 \mathrm{Tg} \mathrm{yr}^{-1}$, respectively. In our approach for constructing the "Best Estimate" of the methane budget, we use a comprehensive and very recent reconstruction of pre-industrial biomass burning emissions (Ferretti et al., 2005) that was constrained by the large atmospheric $\delta^{13} \mathrm{CH}_{4}$ depletion from -47 to $-49 \%$ during 1000-1700 AD. While it is possible to construct a 1000 AD budget with $85 \mathrm{Tg} \mathrm{yr}^{-1}$ of plants, as suggested by Houweling et al. (2006), and with only $15 \mathrm{Tg} \mathrm{yr}^{-1}$ of biomass burning, balancing the atmospheric variations during 1000 $1700 \mathrm{AD}$ requires a reduction in biomass burning to less than $10 \mathrm{Tg} \mathrm{yr}^{-1}$ by $1700 \mathrm{AD}$. However, lightning-induced wildfires alone are very likely to be more than $10 \mathrm{Tg} \mathrm{yr}^{-1}$ (Table 1, note b) so the Ferretti et al. (2005) estimate of pre-industrial biomass burning is still the most reasonable 
Table 2. Uncertainties in the global methane budget for sources (a) and sinks (b).

${ }^{\mathrm{a}} \mathrm{C}_{3}$ and $\mathrm{C}_{4}$ components from Ferretti et al. (2005), Keppler et al. (2006).

b Values from Lassey et al. (2005), Table II. $\varepsilon_{\text {sink }}$ is the sink "kinetic isotope effect" (KIE).

${ }^{c}$ Methane is largely removed from the stratosphere by various processes that discriminate against ${ }^{13} \mathrm{CH}_{4}$ leaving a minor return flux of ${ }^{13} \mathrm{C}$-enriched methane that we ignore. Consequently, and consistently with IPCC assessments, the stratosphere is viewed as a transport-mediated tropospheric sink, a process which is isotopically neutral.

${ }^{d}$ If the recent Allan et al. (2006) estimate of the global chlorine sink strength is used $\left(25 \pm 12 \mathrm{Tg} \mathrm{yr}^{-1}\right)$ the upper limits of global $\mathrm{CH}_{4}$ emissions from plants presented in Table 1 would decrease even further.

\begin{tabular}{cllll}
\hline (a) Source $\delta^{13} \mathrm{CH}_{4}(\% \circ)^{\text {a }}$ & $\mathrm{C}_{3}$ & $\mathrm{C}_{4}$ & $40: 60$ & $60: 40$ \\
Biomass Burning & -25 & -12 & -17.2 & -19.8 \\
Aerobic Plant & -52 & -46.5 & -48.7 & -49.8 \\
Anaerobic & -64 & -54 & -58 & -60 \\
& & & & \\
\hline & & & & \\
(b) Sinks & & $\left(\mathrm{Tg} \mathrm{yr}^{-1}\right)$ & $\varepsilon_{\text {sink }}(\% \circ)$ & \\
OH & & $490 \pm 85$ & $-4.65 \pm 0.75$ & \\
Soil & & $30 \pm 15$ & $-20 \pm 0.2$ & \\
Stratosphere & & $40 \pm 8$ & $0 \pm 0 \mathrm{c}$ & \\
Chlorine & & $10 \pm 9 \mathrm{~d}$ & $-60 \pm 1$ & \\
TOTAL & & $570 \pm 87$ & $-6 \pm 1$ & \\
& & & & \\
\hline
\end{tabular}

reconstruction, even with the inclusion of plant emissions into the methane budget.

The Ferretti et al. (2005) reconstruction of biomass burning is based on a top down approach in which atmospheric measurement uncertainties translate to a reconstructed biomass burning emission uncertainty of $\pm 1 \mathrm{Tg}$. If the biomass burning source varies by this uncertainty, then plant emissions only vary by $\pm 8 \mathrm{Tg} \mathrm{yr}^{-1}$. Therefore small changes in biomass burning do not significantly affect plant emissions and our conclusions. Considering fossil emission uncertainties $\left( \pm 1 \mathrm{Tg} \mathrm{yr}^{-1}\right)$ in a similar way, plant emissions only change by $\pm 2 \mathrm{Tg} \mathrm{yr}^{-1}$, so our conclusions are also not significantly affected by uncertainties in our postulated sources.

To account for the uncertainties associated with the stable carbon isotope values of each source, including that of the plant source isotope value, our approach is to consider two scenarios in which we vary the $\mathrm{C}_{3}: \mathrm{C}_{4}$ plant type ratio between 40:60 and 60:40. As well as being a plausible range of environmental change, this introduces an uncertainty in the isotopic composition of each source which is similar to that associated with bottom up estimates of the isotopic composition of each source type (Table 2a). Since the assigned isotope values of plant emissions are still not known with certainty, the range of $\mathrm{C}_{3}: \mathrm{C}_{4}$ mix allows us to gauge the effect of this uncertainty. We also consider sink uncertainties in the global methane budget so that the total aggregate sink encompasses a large range of errors (Table $2 b$ ) and is not significantly affected by estimated changes in $\mathrm{OH}$ between modern and pre-industrial times (Houweling et al., 2000).
These source and sink uncertainties in the global methane budget cause our calculated results of revised global limits of aerobic methane emissions from plants to contain accumulated uncertainties that are reflected as a relatively large range of possible values (Table 1).

Large pre-industrial $\delta^{13} \mathrm{CH}_{4}$ variations have been partially explained by natural temperature and precipitation changes causing anaerobic and biomass burning emission variations (Ferretti et al., 2005). Even though there is no evidence yet for significant temperature dependency of methane emissions from plants over ambient ranges $\left(\sim 10-30^{\circ} \mathrm{C}\right)$ it is likely that during 1000-1700 AD a cooling climate with increasing moisture availability, together with changes in both anthropogenic deforestation and natural vegetation re-growth, may have combined to maintain near-constant plant emissions, thus explaining the relatively small change in "BestEstimate" plant emissions during 1000-1700 AD (see Table 1).

The "Maximum estimate" of plant emissions is a scenario in which we minimize pre-industrial biomass burning levels and variations in a very conservative way by ignoring both pre-industrial anthropogenic and modern natural biomass burning emissions (see Table 1, note b). However our "Best Estimate" scenario, which is based on more complete and recent evidence of comparatively higher fossil and biomass burning emissions (see Table 1, notes $\mathrm{c}$ and d), is more likely to occur than the "Maximum Estimate" scenario. Thus, while Keppler et al. (2006) argue that preindustrial $\delta^{13} \mathrm{CH}_{4}$ variations (Ferretti et al., 2005) could not be reconciled with a wetland-dominated source, our analysis 
shows that a wetland-dominated pre-industrial source reconstruction with variable biomass burning emissions is more likely to have caused pre-industrial $\delta^{13} \mathrm{CH}_{4}$ variations than one controlled by large plant emission variations.

\section{Conclusions}

Our "Best Estimate" of the methane budget suggests that preindustrial and modern plant emissions are likely to be in the ranges $0-46 \mathrm{Tg} \mathrm{yr}^{-1}$ and $0-176 \mathrm{Tg} \mathrm{yr}^{-1}$, respectively. Therefore, while there is scope in the methane budget for plant emissions, they are not essential to reconcile either the preindustrial or the modern methane budgets.

Although our top-down approach allows increased plant emissions during the industrial era, modern plant emissions are likely to be lower than pre-industrial plant emissions due to the reduction in total biomass that has occurred from anthropogenic deforestation and land use change during 17002000 AD (Schlesinger, 1991). Therefore, during both the pre-industrial and modern eras, the best estimate of global plant emissions is likely to lie in the range $0-46 \mathrm{Tg} \mathrm{yr}^{-1}$ and be at least $80 \%$ lower than proposed by Keppler et al. (2006). The good agreement between our top-down best estimate ( 0 $46 \mathrm{Tg} \mathrm{yr}^{-1}$ ) and bottom-up reassessments of plant emissions ( 10-60 $\mathrm{Tg} \mathrm{yr}^{-1}$ Kirschbaum et al., 2006; $\sim 53 \mathrm{Tg} \mathrm{yr}^{-1}$ Parsons et al., 2006) corroborates our conclusion that plant emissions are likely to be much lower than initially reported by Keppler et al. (2006).

The plant source limits are most sensitive to the sink fractionation and if a larger magnitude fractionation is used (e.g. $-7.4 \%$, Ferretti et al., 2005, which is consistent with a global chlorine sink of $25 \mathrm{Tg} \mathrm{yr}^{-1}$ - see Allan et al., 2006) the upper limits of our best estimate of the plant source would decrease even further.

Besides some small differences between the assumed atmospheric composition and sink-weighted fractionation factor, the main reason for our lower estimate of pre-industrial plant emissions $\left(46 \mathrm{Tg} \mathrm{yr}^{-1}\right)$ compared to the Houweling et al. (2006) estimate $\left(85 \mathrm{Tg} \mathrm{yr}^{-1}\right)$ is that the Houweling et al. (2006) estimate of biomass burning emissions at $1000 \mathrm{AD}$ $\left(15 \mathrm{Tg} \mathrm{yr}^{-1}\right)$ is significantly lower than ours $\left(25 \mathrm{Tg} \mathrm{yr}^{-1}\right)$. However, the atmospheric constraint during 1000-1700 AD causes biomass burning in the Houweling et al. (2006) budget to decrease below the lower feasible limit of natural wildfires.

Clearly, a lot remains to be learnt about the pre-industrial and modern methane budgets. Further field and laboratory studies are needed to better define methane emissions from plants and new ice core records of carbon and hydrogen isotopes in atmospheric methane throughout the Holocene are required to better constrain the pre-industrial methane budget.
Acknowledgements. Staff from the following institutes supported the Antarctic field work: the Australian Antarctic Program; the Australian Bureau of Meteorology; CSIRO Marine and Atmospheric Research; and Australian Nuclear Science and Technology Organisation. Supported US-NSF grant no. OPP0087357 and New Zealand Foundation for Research Science and Technology grant no. C01X0204.

Edited by: A. B. Guenther

\section{References}

Allan, W., Struthers, H. A., and Lowe, D. C.: Methane carbon isotope effects caused by atomic chlorine in the marine boundary layer: Global model results compared with southern hemisphere measurements, J. Geophys. Res. D., in press, 2006.

Andreae, M. O. and Merlet, P.: Emission of trace gases and aerosols from biomass burning, Global Biogeochem. Cycles, 15, 955966, 2001.

Carmo, J. B., Keller, M., Dias, J. D., Camargo, P. B., and Crill, P.: A source of methane from upland forests in the Brazilian Amazon, Geophys. Res. Lett., 33, L04809, doi:10.1029/2005GL025436, 2006.

Crutzen, P. J., Sanhueza, E., and Brenninkmeijer, C. A. M.: Methane production from mixed tropical savannah and forest vegetation in Venezuela, Atmos. Chem. Phys. Discuss., 6, 30933097, 2006,

http://www.atmos-chem-phys-discuss.net/6/3093/2006/.

Etiope, G.: New Directions: GEM - Geologic Emissions of Methane, the missing source in the atmospheric methane budget, Atmos. Environ., 38, 3099-3100, 2004.

Ferretti, D. F., Miller, J. B., White, J. W. C., Etheridge, D. M., Lassey, K. R., Lowe, D. C., MacFarling Meure, C. M., Dreier, M. F., Trudinger, C. M., Ommen, T. D. V., and Langenfelds, R. L.: Unexpected changes to the global methane budget over the last 2000 years, Science, 309, 1714-1717, 2005.

Frankenberg, C., Meirink, J. F., v. Weele, M., Platt, U., and Wagner, T.: Assessing methane emissions from space-borne observations, Science, 308, 1010-1014, 2005.

Frankenberg, C., Meirink, J. F., Bergamaschi, P., Goede, A. P. H., Heimann, M., Körner, S., Platt, U., v. Weele, M., and Wagner, T.: Satellite chartography of atmospheric methane from SCIAMACHY on board ENVISAT: Analysis of the years 2003 and 2004, J. Geophys. Res., 111, D07303, doi:10.1029/2005JD006235, 2006.

Houweling, S., Dentener, F., and Lelieveld, J.: Simulation of preindustrial methane to constrain the global source strength of natural wetlands, J. Geophys. Res., 105, 17 243-17 255, 2000.

Houweling, S., Rockmann, T., Aben, I., Keppler, F., Krol, M., Meirink, J. F., Dlugokencky, E. J., and Frankenberg, C.: Atmospheric constraints on global emissions of methane from plants, Geophys. Res. Lett., 33, L15821, doi:10.1029/2006GL026162, 2006.

Judd, A. G., Charlier, R. H., Lacroix, A., Lambert, G., and Rouland, C.: Sources, Sinks, and Role in Global Change, in: Atmospheric Methane, edited by: Khalil, M. A. K., Springer-Verlag, Berlin, 432-456, 1993. 
Keppler, F., Hamilton, J. T. G., Braß, M., and Röckmann, T.: Methane emissions from terrestrial plants under aerobic conditions, Nature, 439, 187-191, 2006.

Kirschbaum, M. U. F., Bruhn, D., Etheridge, D. M., Evans, J. R., Farquhar, G. D., Gifford, R. M., Paul, K. I., and Winters, A. J.: A Comment on the Quantitative Significance of Aerobic Methane Release by Plants, Functional Plant Biol., 33, 521-530, 2006.

Lassey, K. R., Scheehle, E. A., and Kruger, D.: Towards reconciling national emission inventories for methane with the global budget, Environ. Sci., 2, 193-204, 2005.

Scheehle, E. A. and Kruger, D.: Global anthropogenic methane and nitrous oxide emissions, Energy J., special issue 3, MultiGreenhouse Gas Mitigation and Climate Policy, 2006.

Schiermeier, Q.: The methane mystery, Nature, 442, 730-731, 2006.
Schlesinger, W. H.: Biogeochemistry: An analysis of global change, Academic Press, San Diego, 1991.

Subak, S.: Methane from the house of Tudor and the Ming Dynasty: Anthropogenic emissions in the sixteenth century, Chemosphere, 29, 843-854, 1994.

Venevsky, S.: Estimate of global carbon emissions to the atmosphere from lightning and human induced fires, in: Integrated Land Ecosystem-Atmosphere Process Study, Proceedings of the 1st iLEAPS Science Conference, edited by: Reissell, A. A., Boulder Colorado, USA, 2006. 